\title{
STRATEGI PENGEMBANGAN KAWASAN PERTANIAN PADI BERBASIS PREFERENSI PETANI DAN SUMBERDAYA LAHAN DI KABUPATEN BANGKA SELATAN
}

\section{Development Strategy of Rice Farming Area Based on Farmer's Preferences and Land Resource in South Bangka Regency}

\author{
Ardilles Akbar1) ${ }^{*}$ Untung Sudadi2), dan Komarsa Gandasasmita2) \\ 1) Alumni Program Studi Ilmu Perencanaan Wilayah, Sekolah Pascasarjana IPB, Jl. Raya Darmaga, Gedung Andi \\ Hakim Nasoetion Kampus IPB Darmaga Bogor 16680 \\ 2) Departemen Ilmu Tanah dan Sumberdaya Lahan, Fakultas Pertanian IPB, Jl. Meranti Kampus IPB Darmaga \\ Bogor 16680
}

\begin{abstract}
As the largest rice producer in the Province of Bangka Belitung Archipelago, South Bangka Regency has not until now been capable of being self-sufficiency. Increasing tin mining and plantation activities in the region trigger farmers to switch their professions to be tin miners or working in tin mining supporting sectors. This food security related problems must be anticipated with appropriate strategies. This research aimed at to: (1) analyze priorities of rice-farming development strategy based on farmer's preferences hierarchy, (2) identify land resource available for rice farming development based on Landsat interpretation and land suitability evaluation, and (3) set up rice-farming development directions in South Bangka Regency. The first two strategies prioritized by the farmers prioritized strategies were to develop agricultural infrastructures and rice production facilities. Farmers of the developed and developing areas preferred improvement in product marketing and government incentives, respectively as another important strategy. Land resources suitable for upland rice cultivation were identified as of S1 and S3 class, covering areas of respectively 8,460 and 12,630 ha, while those for wetland rice were of S1, S2, and S3 class, covering areas of respectively 8,680; 30; and 3,070 ha. For the developed and not developed areas, the rice development strategies were respectively directed primarily to increase farming productivity and to protect the existence of rice farming activities.
\end{abstract}

Keywords: Development strategy, farmer's preference, land resource, rice, South Bangka Regency

\begin{abstract}
ABSTRAK
Sebagai penghasil padi terbesar di Provinsi Kepulauan Bangka Belitung, Kabupaten Bangka Selatan belum mampu mencapai swasembada beras. Meningkatnya aktivitas penambangan timah dan perkebunan di wilayah ini memicu petani padi untuk beralih profesi menjadi penambang timah atau bekerja di sektor penunjang pertambangan timah. Diperlukan strategi yang tepat untuk mengantisipasi permasalahan terkait ketahanan pangan tersebut. Penelitian ini bertujuan: (1) menganalisis prioritas strategi pengembangan pertanian padi berdasarkan hirarki preferensi petani, (2) mengidentifikasi sumberdaya lahan tersedia untuk pengembangan pertanian padi berbasis interpretasi citra Landsat dan evaluasi kesesuaian lahan, serta (3) menyusun arahan pengembangan lahan pertanian padi di Kabupaten Bangka Selatan. Dua strategi utama yang diprioritaskan petani adalah pengembangan infrastruktur pertanian dan sarana-prasarana produksi padi. Strategi penting lainnya yang dipilih petani daerah cukup berkembang adalah peningkatan pemasaran hasil, sedangkan petani daerah belum berkembang lebih memilih peningkatan insentif dari pemerintah. Sumberdaya lahan yang sesuai untuk budidaya padi ladang teridentifikasi berkelas S1 dan S3 masing-masing seluas 8,460 dan 12,630 ha, sedangkan untuk padi sawah berkelas S1, S2 dan S3 masingmasing seluas 8,680; 30 dan 3,070 ha. Strategi pengembangan di daerah cukup berkembang terutama diarahkan untuk peningkatan produktivitas usahatani, sedangkan di daerah berkembang untuk melindungi eksistensi aktivitas pertanian padi.
\end{abstract}

Kata kunci: Strategi pengembangan, preferensi petani, sumberdaya lahan, padi, Kabupaten Bangka Selatan

\section{PENDAHULUAN}

Menurut UU Nomor 18 tahun 2012 tentang Pangan, ketahanan pangan adalah kondisi terpenuhinya pangan bagi negara sampai dengan perseorangan, yang tercermin dari tersedianya pangan yang cukup, baik jumlah maupun mutunya, aman, beragam, bergizi, merata dan terjangkau serta tidak bertentangan dengan agama, keyakinan dan budaya masyarakat, untuk dapat hidup sehat, aktif dan produktif secara berkelanjutan. Dengan demikian, ketahanan pangan merupakan salah satu faktor penentu stabilitas nasional suatu negara. Berbagai gejolak sosial dan politik dapat terjadi jika ketahanan pangan terganggu (Ismet, 2007).

Kesenjangan produksi padi yang signifikan antar provinsi, khususnya antara provinsi di Pulau Jawa dengan 
luar Pulau Jawa, merupakan salah satu tantangan dalam mencapai ketahanan pangan nasional. Tingkat kepadatan penduduk agraris, yaitu nisbah antara jumlah tenaga kerja sektor pertanian pangan dengan luasan lahan pertanian pangan, antar provinsi juga timpang. Terkait kedua hal ini, Provinsi Kepulauan Bangka Belitung (Prov. Kep. Babel) dapat diindikasikan menghadapi masalah ketahanan pangan karena mengalami defisit produksi padi sementara kepadatan penduduk agrarisnya rendah, yaitu hanya 55 jiwa km ${ }^{-2}$ (BPS, 2012; Kementerian Pertanian, 2012).

Prov. Kep. Babel merupakan penghasil timah terbesar di Indonesia (BPS, 2012). Pada tahun 2012, perubahan lahan yang cukup besar telah terjadi pada kawasan hutan yang berubah menjadi lahan terbuka dan lahan tambang (Dinas Kehutanan Prov. Kep. Babel, 2012). Masyarakat daerah tambang cenderung mengubah mata pencahariannya dari pertanian ke pertambangan atau sektor penunjang pertambangan (Zaki et al., 2012). Hal ini dapat memicu petani padi untuk beralih profesi atau mengalihfungsikan lahan pertanian padinya. Bila kedua hal ini terjadi, maka ketahanan pangan di Prov. Kep. Babel dapat semakin terancam.

Kabupaten Bangka Selatan (Kab. Basel) adalah penghasil padi terbesar di Prov. Kep. Babel. Namun, produksi padinya hanya mampu mencukupi 54\% kebutuhan beras penduduknya, sementara $46 \%$ lainnya berasal dari Pulau Jawa dan Sumatera (Pemerintah Prov. Kep. Babel, 2012). Hal ini menunjukkan bahwa sebagai sentra produksi padi, Kab. Basel hingga saat ini belum mampu berswasembada beras.

Hasil pemetaan sosial daerah-daerah penghasil minyak dan gas (migas) oleh Satuan Kerja Sementara Kegiatan Hulu Migas menunjukkan bahwa pada tahun 2012 tenaga kerja di bidang pertambangan dan penggalian di Kab. Basel meningkat $3.38 \%$, sementara di bidang pertanian menurun $6.12 \%$. Dengan laju pertumbuhan penduduk lebih dari $2 \%$ per tahun, data tersebut menginformasikan bahwa pertambahan penduduk sampai saat ini belum berpengaruh positif terhadap pengembangan pertanian karena lebih disebabkan oleh ketertarikan pendatang terhadap pertambangan timah. Lebih lanjut, angka sementara hasil pencacahan lengkap Sensus Pertanian 2013 di Kab. Basel menunjukkan penurunan sejumlah 297 rumah tangga pertanian selama sepuluh tahun terakhir. Hal ini mengindikasikan perlunya strategi untuk mempertahankan dan mengembangkan kawasan pertanian padi sesuai amanat UU No. 41 tahun 2009 tentang Perlindungan Lahan Pertanian Berkelanjutan dan PP No. 12 tahun 2012 tentang Insentif Perlindungan Lahan Pertanian Pangan Berkelanjutan. Efektivitas penerapan strategi tersebut sangat ditentukan oleh preferensi petani dan ketersediaan sumberdaya lahan pertanian.

Berdasarkan latar belakang tersebut, penelitian ini bertujuan: (1) menganalisis prioritas strategi pengembangan pertanian padi berdasarkan hirarki preferensi petani, (2) mengidentifikasi sumberdaya lahan yang sesuai untuk pengembangan pertanian padi berbasis interpretasi citra Landsat dan evaluasi kesesuaian lahan serta (3) menyusun arahan pengembangan lahan pertanian padi di Kabupaten Bangka Selatan.

\section{BAHAN DAN METODE}

\section{Bahan dan Alat}

Penelitian ini menggunakan data primer dan data sekunder. Data primer diperoleh secara langsung dari obyek penelitian melalui wawancara, pengisian kuesioner dan cek lapangan. Data primer juga meliputi data spasial citra Landsat. Data sekunder yang terdiri atas data spasial dan atribut dikumpulkan dari Bappeda Kab. Basel, Dinas Pertanian dan Kehutanan Kab. Basel, Dinas Kehutanan Prov. Kep. Babel, BPS Kab. Basel, BPS dan Balai Penelitian Tanaman Pangan, Kementerian Pertanian.

Responden penelitian terdiri atas petani dan instansi terkait yang dipilih secara purposive berdasarkan pertimbangan pengetahuan dan kompetensi terhadap beberapa strategi pengembangan pertanian sesuai dengan UU No. 41 tahun 2009 dan PP No. 12 tahun 2012. Jumlah responden petani ditetapkan berdasarkan rumus Slovin (Sugiyono, 2006) dengan batas toleransi kesalahan 2\%, sehingga dari 100 kelompok tani padi di Kab. Basel didapatkan 25 sampel responden ketua kelompok tani. Responden petani dibagi menjadi petani daerah belum berkembang dan cukup berkembang berdasarkan kriteria tahap perkembangan kawasan pertanian menurut Peraturan Menteri Pertanian No. 50 tahun 2012 tentang Pedoman Pengembangan Kawasan Pertanian.

Sampel responden instansi terkait dipilih berdasarkan keterkaitan tugas pokok dan fungsinya dengan pertanian padi berkelanjutan, yaitu: Badan Pelaksana Penyuluh dan Ketahanan Pangan (BPPKP) Kab. Basel, Dinas Pertanian dan Kehutanan Kab. Basel, Dinas Pekerjaan Umum (PU) Kab. Basel, Bappeda Kab. Basel, Dinas Pertanian, Perkebunan dan Peternakan Prov. Kep. Babel Bidang Prasarana dan Sarana Pertanian (PSP) dan Teknologi Hasil Pertanian (THP), Bappeda Prov. Kep. Babel dan Universitas Bangka Belitung.

\section{Metode Penelitian}

\section{Analisis Preferensi Responden terhadap Strategi Pengembangan Pertanian Padi}

Analisis preferensi responden petani padi dan instansi terkait terhadap prioritas strategi untuk mempertahankan dan mengembangkan lahan pertanian padi dilakukan dengan metode Analytical Hierarcy Process (AHP). AHP digunakan sebagai alat bantu untuk menentukan kriteria penentuan prioritas strategi. Hirarki yang digunakan terdiri atas tiga aras, yaitu: aras 1 (tujuan), aras 2 (strategi) dan aras 3 (aksi, yaitu kegiatan yang berasal dari pengembangan strategi pada aras 2).

Alternatif strategi yang dianalisis merujuk pada UU No. 41 tahun 2009 dan PP No. 12 tahun 2010 yang telah diseleksi berdasarkan kesesuaian dengan kondisi dan budaya petani padi di Kab. Basel. Strategi tersebut adalah: pengembangan infrastruktur pertanian (A), penyediaan sarana dan prasarana produksi pertanian (B), adanya lembaga keuangan yang menyediakan kredit untuk usahatani padi (C), pemberian penghargaan kepada petani berprestasi (D) dan pembinaan pemasaran di tingkat lapangan $(\mathrm{E})$. 
Identifikasi Konsistensi Lahan Aktual dan Potensial untuk Kawasan Pertanian Padi dengan RTRWK

Analisis ini terdiri atas tahapan: (1) interpretasi citra Landsat, (2) dijitasi peta satuan lahan dan peta kesesuaian lahan berdasarkan analisis terrain, dan (3) analisis kesesuaian lahan padi aktual dan potensial dengan RTRWK Kab. Basel.

Interpretasi citra merupakan kegiatan mengkaji foto udara atau citra dengan maksud untuk mengidentifikasi obyek yang tergambar dalam citra dan menilai arti penting obyek tersebut (Estes dan Simonett, 1975). Rangkaian kegiatan yang dilakukan dalam pengenalan obyek yang tergambar pada citra meliputi: deteksi, identifikasi, dan analisis. Deteksi adalah pengamatan atas ada atau tidaknya suatu obyek pada citra. Identifikasi adalah upaya untuk mencirikan obyek yang dideteksi dengan keterangan yang cukup menggunakan unsur interpretasi citra. Pada tahap analisis dikumpulkan keterangan lebih lanjut untuk membuat kesimpulan (Lintz dan Simonett, 1976). Peta kesesuaian lahan berbasis satuan lahan diterbitkan dan diperoleh dari BPTP Prov. Kep. Babel. Analisis konsistensi lahan padi aktual dan potensial dengan pola ruangnya dalam RTRWK dilakukan untuk mengetahui kesesuaian rencana pemerintah dengan keadaan aktual tutupan lahan dan kesesuaian lahan untuk pertanian padi.

\section{HASIL DAN PEMBAHASAN}

\section{Preferensi Responden terhadap Strategi Pengembangan Pertanian Padi}

\section{Prioritas Strategi Menurut Seluruh Responden Petani}

Menurut seluruh responden petani, urutan preferensi strategi (Tabel 1) dari yang tertinggi ke terendah adalah: (1) pengembangan infrastruktur pertanian $(27.2 \%)$, (2) penyediaan sarana dan prasarana produksi pertanian (27.0\%), (3) pembinaan pemasaran di tingkat lapangan (19.1\%), (4) adanya lembaga keuangan penyedia kredit usahatani padi $(14.1 \%)$ dan (5) pemberian penghargaan kepada petani berprestasi (bobot 12.5\%).

Tabel 1. Prioritas strategi berdasarkan preferensi responden

\begin{tabular}{|c|c|c|c|c|c|c|c|c|c|}
\hline & \multirow[t]{2}{*}{ Strategi } & \multicolumn{2}{|c|}{ Seluruh Petani } & \multicolumn{2}{|c|}{$\begin{array}{c}\text { Petani Daerah } \\
\text { Cukup } \\
\text { berkembang } \\
\end{array}$} & \multicolumn{2}{|c|}{$\begin{array}{l}\text { Petani Daerah } \\
\text { Berkembang }\end{array}$} & \multicolumn{2}{|c|}{ Instansi Terkait } \\
\hline & & $\begin{array}{c}\text { Bobot } \\
(\%)\end{array}$ & \# & $\begin{array}{c}\text { Bobot } \\
(\%)\end{array}$ & \# & $\begin{array}{c}\text { Bobot } \\
(\%)\end{array}$ & $\#$ & $\begin{array}{c}\text { Bobot } \\
(\%)\end{array}$ & \# \\
\hline A & $\begin{array}{l}\text { Pengembangan infrastruktur } \\
\text { pertanian }\end{array}$ & 27.2 & 1 & 27.1 & 1 & 26.9 & 2 & 26.5 & 2 \\
\hline B & $\begin{array}{l}\text { Penyediaan sarana dan prasarana } \\
\text { produksi pertanian }\end{array}$ & 27.0 & 2 & 24.0 & 3 & 29.5 & 1 & 27.2 & 1 \\
\hline $\mathrm{C}$ & $\begin{array}{l}\text { Adanya lembaga keuangan penyedia } \\
\text { kredit usahatani padi }\end{array}$ & 14.1 & 4 & 11.7 & 5 & 16.5 & 3 & 17.8 & 3 \\
\hline $\mathrm{D}$ & $\begin{array}{l}\text { Pemberian penghargaan kepada } \\
\text { petani berprestasi }\end{array}$ & 12.5 & 5 & 12.7 & 4 & 12.1 & 5 & 11.6 & 5 \\
\hline \multirow[t]{2}{*}{$\mathrm{E}$} & $\begin{array}{l}\text { Pembinaan pemasaran di tingkat } \\
\text { lapangan }\end{array}$ & 19.1 & 3 & 24.3 & 2 & 15.1 & 4 & 16.9 & 4 \\
\hline & Jumlah & 100 & & 100 & & 100 & & 100 & \\
\hline
\end{tabular}

\# urutan preferensi prioritas strategi

\section{Prioritas Strategi Menurut Responden Petani Daerah Cukup Berkembang}

Berdasarkan data BPS Kab. Basel tahun 2012 dan Dinas Pertanian dan Kehutanan Kab. Basel diketahui bahwa desa Rias dan Serdang di kecamatan Toboali termasuk daerah cukup berkembang dalam budidaya pertanian padi di Kab. Basel.

Menurut responden petani daerah cukup berkembang (Tabel 1), urutan preferensi strategi dari yang tertinggi ke terendah adalah: (1) pengembangan infrastruktur pertanian $(27.1 \%)$, (2) pembinaan pemasaran di tingkat lapangan (24.3\%), (3) penyediaan sarana dan prasarana produksi pertanian $(24.0 \%)$, (4) pemberian penghargaan kepada petani berprestasi (12.7\%) dan (5) adanya lembaga keuangan penyedia kredit usahatani padi (11.7\%).

\section{Prioritas Strategi Menurut Responden Petani Daerah Belum Berkembang}

Daerah yang termasuk belum berkembang dalam budidaya pertanian padi di Kab. Basel adalah kecamatan Air Gegas, Payung dan Simpang Rimba.
Menurut responden petani daerah berkembang (Tabel 1), urutan preferensi strategi dari yang tertinggi ke terendah adalah: (1) penyediaan sarana dan prasarana produksi pertanian $(29.5 \%)$, (2) pengembangan infrastruktur pertanian (26.9\%), (3) adanya lembaga keuangan penyedia kredit usahatani padi (16.5\%), (4) pembinaan pemasaran di tingkat lapangan (15.1\%) dan (5) pemberian penghargaan kepada petani berprestasi (12.1\%).

\section{Prioritas Strategi Menurut Responden Instansi Terkait}

Instansi terkait adalah para pihak yang turut berperan menentukan keberhasilan pengembangan kawasan pertanian padi agar berkelanjutan. Prioritas strategi menurut preferensi instansi terkait dapat dibandingkan dengan yang diinginkan petani. Dalam hal ini, persepsi perihal prioritas strategi antar dan antara instansi terkait dengan petani seharusnya berkesesuaian dan sinergis.

Menurut responden instansi terkait (Tabel 1), urutan preferensi strategi dari yang tertinggi ke terendah adalah: (1) penyediaan sarana dan prasarana produksi pertanian $(27.2 \%)$, (2) pengembangan infrastruktur pertanian $(26.5 \%)$, (3) adanya lembaga keuangan penyedia 
kredit usahatani padi (17.8\%), (4) pembinaan pemasaran di tingkat lapangan $(16.9 \%)$ dan (5) pemberian penghargaan kepada petani berprestasi $(11.6 \%)$.

\section{Penutupan/Penggunaan Lahan Aktual}

Informasi mengenai sebaran dan luasan penutupan/penggunaan lahan aktual diperoleh dari hasil interpretasi citra Landsat yang diakuisisi pada Juni 2013 dan Juni 2011. Citra Landsat tahun 2011 digunakan untuk mengetahui tutupan lahan yang tertutup awan pada citra Landsat tahun 2013. Hasil interpretasi disajikan pada Tabel 2 dan Gambar 1.

Tabel 2. Luasan dan persentase tutupan lahan aktual Kabupaten Bangka Selatan tahun 2013

\begin{tabular}{|c|c|c|c|c|c|c|}
\hline Tutupan Lahan & Semak Belukar & Hutan & Tambang & Belukar Rawa & Perkebunan & Tanah Terbuka \\
\hline Luas (ha) & 234,060 & 42,810 & 21,580 & 15,580 & 9,790 & 8,650 \\
\hline Luas $(\%)$ & 67.21 & 12.29 & 6.20 & 4.48 & 2.81 & 2.49 \\
\hline Tutupan Lahan & $\begin{array}{c}\text { Pertanian Lahan } \\
\text { Kering }\end{array}$ & Sawah & Permukiman & Rawa & Tambak & $\begin{array}{c}\text { Tubuh } \\
\text { Air }\end{array}$ \\
\hline Luas (ha) & 4,940 & 4,620 & 3,760 & 2,440 & 50 & 10 \\
\hline Luas $(\%)$ & 1.42 & 1.33 & 1.08 & 0.7 & 0.013 & 0.003 \\
\hline
\end{tabular}

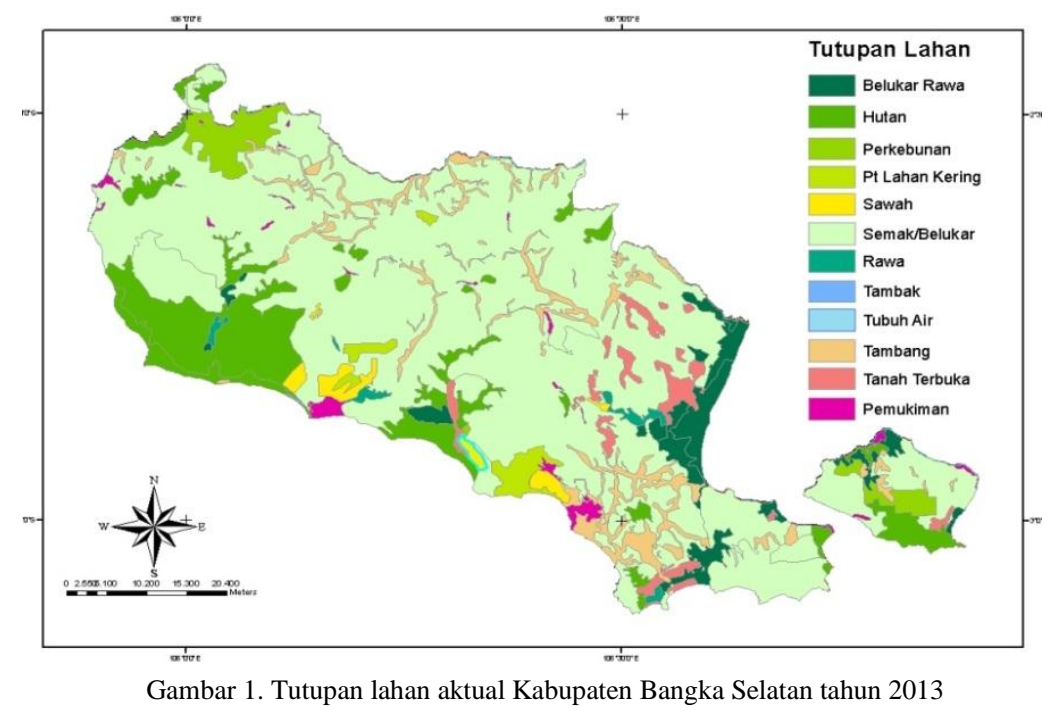

\section{Kesesuaian Lahan untuk Tanaman Padi}

Terdapat 3 ordo tanah yang dominan di Kab. Basel, yaitu: Ultisols, Entisols dan Inceptisols. Ordo Histosols juga terdapat di Kab. Basel, namun sebarannya terbatas. Kemiringan lahan yang dominan di Kab. Basel adalah kelas elevasi 1 (datar). Evaluasi kesesuaian lahan dilakukan oleh BPTP Prov. Kep. Babel (2006) dengan asumsi adanya masukan perbaikan faktor-faktor pembatas pada tingkat "sedang" berdasarkan kriteria rejim suhu udara (tc), media perakaran (rc) dan bahaya erosi (eh), tanpa mempertimbangkan retensi hara (nr), ketersediaan hara (ne) dan ketersediaan air (wa).

\section{Konsistensi Pola Ruang Pertanaman Padi RTRWK dengan Tutupan Lahan Aktual}

Dari analisis konsistensi pola ruang pertanaman padi menurut RTRWK dengan tutupan lahan aktual ditemukan lokasi rencana pencetakan sawah baru yang terletak di areal hutan, permukiman, tambak dan tambang (3,975 ha). Hal ini diduga pada saat penyusunan RTRWK areal tersebut tutupan lahannya belum seperti keadaan saat ini. Rencana ini disarankan untuk dialihkan ke lokasi lain yang lebih sesuai.

Pola ruang untuk pertanaman padi pada RTRWK seluas 26,150 ha. Dengan mengeluarkan areal yang tidak sesuai lagi untuk pencetakan sawah baru (hutan, permukiman, tambak dan tambang), maka lahan pada RTRWK yang sesuai untuk pengembangan pertanian padi seluas 22,170 ha (Gambar 2). Luasan ini termasuk areal padi aktual (4,620 ha), sehingga yang berpotensi untuk pengembangan areal pertanaman padi seluas 17,550 ha.

\section{Area Potensial untuk Pengembangan Pertanian Padi Berbasis Kesesuaian Lahan}

Dengan menerapkan prosedur evaluasi kesesuaian lahan untuk tanaman padi pada areal pengembangan (Gambar 2), maka dapat didelineasi areal dengan kelas kesesuaian S1, S2 dan/atau S3 (Tabel 3) untuk pertanaman padi sawah atau padi ladang. Dengan demikian dapat ditentukan prioritas areal yang sebaiknya dikembangkan terlebih dahulu terkait dengan potensi kesesuaian lahannya. 


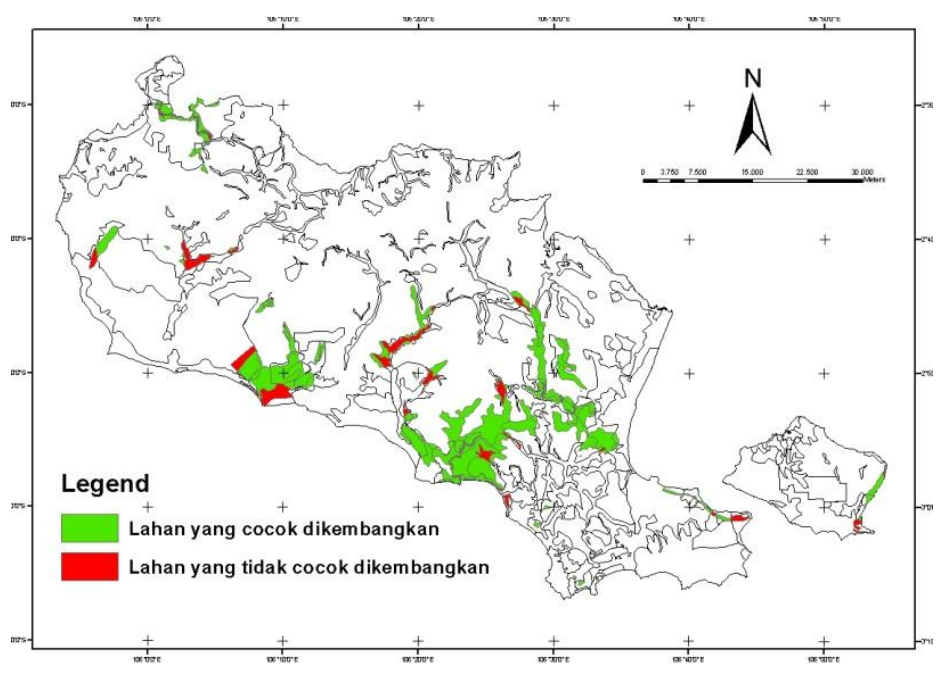

Gambar 2. Peta potensi sumberdaya lahan untuk pengembangan pertanian padi yang sesuai dengan RTRWK Kabupaten Bangka Selatan

Tabel 3. Luas sumberdaya lahan potensial untuk pengembangan pertanian padi sawah dan padi ladang menurut kelas kesesuaian lahan di Kab. Bangka Selatan

\begin{tabular}{cccc}
\hline \multirow{2}{*}{ Komoditas } & \multicolumn{4}{c}{ Kelas Kesesuaian Lahan (luas dalam hektar) } \\
\cline { 2 - 4 } & $\mathrm{S} 1$ & $\mathrm{~S} 2$ & $\mathrm{~S} 3$ \\
\hline Padi Ladang & 8,460 & - & 12,630 \\
Padi Sawah & 8,680 & 30 & 3,070 \\
\hline
\end{tabular}

Ket: S1 = sangat sesuai, S2 = agak sesuai, S3 = sesuai marjinal

Dari hasil analisis (Tabel 3) diketahui bahwa pengembangan pertanian padi ladang dapat dilakukan di tiga kelas kesesuaian lahan, yaitu S1, S2 dan S3. Kelas S1 memiliki luasan 8,460 ha dan S3 12,630 ha. Kelas S2 hanya meliputi luasan kurang dari 10 ha. Oleh karena penelitian ini beskala semi detil, maka luasan yang bernilai satuan dalam hektar diabaikan. Untuk padi sawah, pengembangan dapat dilakukan pada areal dengan kelas kesesuaian S1, S2 dan S3. Kelas S1 memiliki luasan 8,680 ha, S2 30 ha dan S3 3,070 ha. Perbedaan luasan areal yang sesuai untuk pengembangan padi dengan kondisi tutupan lahan aktual disebabkan oleh perbedaan kelas kesesuaian lahan untuk padi sawah dan padi ladang di masing-masing satuan lahan.

\section{Strategi Pengembangan Kawasan Pertanian Padi di Kabupaten Bangka Selatan}

Penyusunan strategi pengembangan kawasan pertanian didasarkan atas: (1) beras merupakan komoditas strategi di Kab. Basel, (2) kawasan yang akan dikembangkan merupakan kawasan yang direncanakan dalam RTRW sebagai kawasan pertanian padi, (3) kawasan yang akan dikembangkan tidak termasuk daerah yang tidak sesuai untuk pertanian yaitu daerah pertambangan, permukiman, tambak, dan kawasan hutan lindung, (4) kawasan yang dikembangkan memiliki kelas kesesuaian lahan S1, S2, dan S3, dan (5) strategi yang akan diterapkan sesuai dengan preferensi petani untuk pengembangan pertanian padi berkelanjutan dalam hal peningkatan produktivitas dan untuk mempertahankan profesi petani. Pertanian berkelanjutan adalah suatu ekosistem lahan yang berkelanjutan, layak secara ekonomis, dan diterima dengan baik secara sosial (Qiu et al., 2007).

Metode sintesis digunakan untuk menggabungkan hasil analisis sebelumnya. Sintesis antara hasil analisis preferensi petani terhadap prioritas strategi pengembangan dengan analisis kesesuaian lahan untuk pengembangan pertanian padi berdasarkan penapisan tutupan lahan aktual dan potensial dengan pola ruang pertanaman padi menurut RTRWK, menghasilkan dua klasifikasi strategi pengembangan kawasan pertanian padi berkelanjutan di Kab. Basel. Penetapan lokasi pengembangan padi sawah dan padi ladang diarahkan dengan tujuan agar daerah tersebut dikembangkan untuk padi sawah atau padi ladang.

Strategi I ditujukan untuk peningkatan produktivitas usahatani padi, sedangkan Strategi II untuk mempertahankan lahan padi eksisting atau profesi petani padi. Strategi I disajikan pada Tabel 4 dan Gambar 3, sedangkan Strategi II disajikan pada Tabel 5 dan Gambar 4.

Tabel 4. Prioritas strategi peningkatan produktivitas usahatani padi di Kabupaten Bangka Selatan

\begin{tabular}{ll}
\hline Prioritas & Deskripsi \\
\hline Prioritas 1 & Lahan pengembangan dengan kelas kesesuaian S1 di daerah usahatani padi cukup berkembang \\
Prioritas 2 & Lahan pengembangan dengan kelas kesesuaian S2 di daerah usahatani padi cukup berkembang \\
Prioritas 3 & Lahan pengembangan dengan kelas kesesuaian S3 di daerah usahatani padi cukup berkembang \\
Prioritas 4 & Lahan pengembangan dengan kelas kesesuaian S1 di daerah usahatani padi belum berkembang \\
Prioritas 5 & Lahan pengembangan dengan kelas kesesuaian S2 di daerah usahatani padi belum berkembang \\
Prioritas 6 & Lahan pengembangan dengan kelas kesesuaian S3 di daerah usahatani padi belum berkembang \\
\hline
\end{tabular}



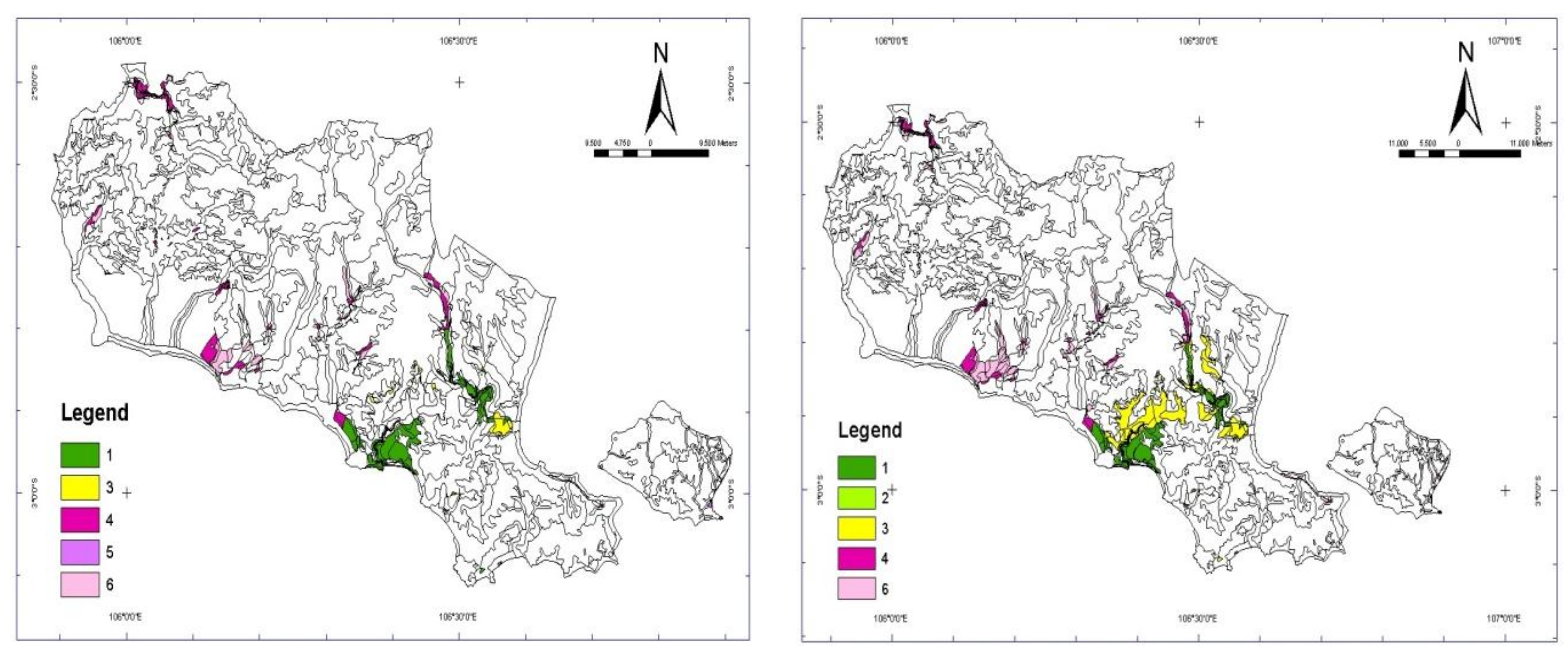

Gambar 3. Peta arahan lokasi peningkatan produktivitas padi sawah (kiri) dan padi ladang (kanan).

Tabel 5. Prioritas strategi untuk mempertahankan profesi petani padi di Kab. Bangka Selatan

\begin{tabular}{ll}
\hline Prioritas & Deskripsi \\
\hline Prioritas 1 & Lahan pengembangan dengan kelas kesesuaian S3 di daerah usahatani padi belum berkembang \\
Prioritas 2 & Lahan pengembangan dengan kelas kesesuaian S2 di daerah usahatani padi belum berkembang \\
Prioritas 3 & Lahan pengembangan dengan kelas kesesuaian S1 di daerah usahatani padi belum berkembang \\
Prioritas 4 & Lahan pengembangan dengan kelas kesesuaian S3 di daerah usahatani padi cukup berkembang \\
Prioritas 5 & Lahan pengembangan dengan kelas kesesuaian S2 di daerah usahatani padi cukup berkembang \\
Prioritas 6 & Lahan pengembangan dengan kelas kesesuaian S1 di daerah usahatani padi cukup berkembang \\
\hline
\end{tabular}
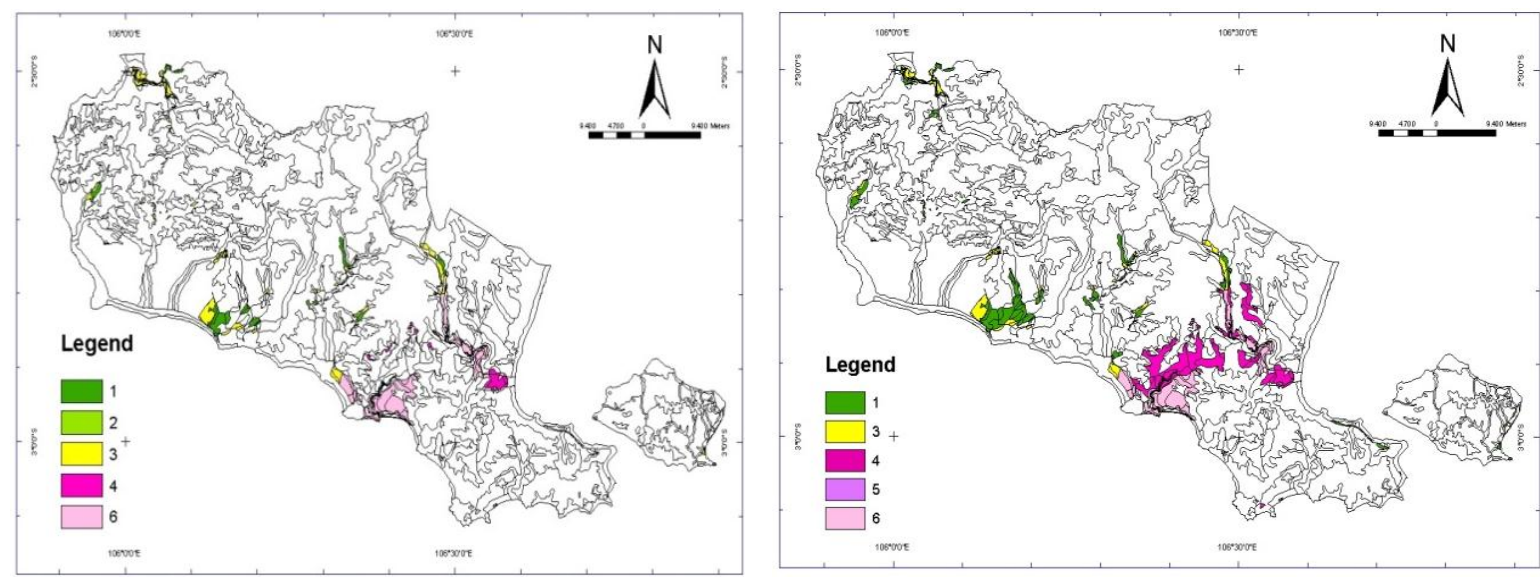

Gambar 4. Peta arahan lokasi penerapan strategi untuk mempertahankan profesi petani padi sawah (kiri) dan padi ladang (kanan).

\section{SIMPULAN}

1. Strategi prioritas preferensi petani dan pemangku kepentingan untuk pengembangan pertanian padi di Kabupaten Bangka Selatan adalah pengembangan infrastruktur pertanian dan peningkatan saranaprasarana produksi padi. Petani daerah cukup berkembang juga mempertimbangkan perlunya strategi peningkatan pemasaran hasil, sedangkan petani daerah berkembang masih mengharapkan insentif dari pemerintah.

2. Pengembangan pertanian padi di Kabupaten Bangka Selatan dapat dilakukan pada lahan dengan kelas kesesuaian S1 seluas 8,460 ha dan S3 seluas 12,630 ha untuk padi ladang serta kelas S1 seluas 8,680 ha, S2 seluas 30 ha dan S3 seluas 3,070 ha untuk padi sawah.
3. Pengembangan pertanian padi berkelanjutan di Kabupaten Bangka Selatan dapat dilakukan dengan dua strategi untuk meningkatkan produktivitas padi atau untuk mempertahankan profesi petani padi. Strategi pertama diprioritaskan pada areal usahatani padi cukup berkembang dengan kelas kesesuaian lahan S1, sedangkan strategi kedua pada areal usahatani padi berkembang dengan kelas kesesuaian lahan S3.

\section{DAFTAR PUSTAKA}

[BPS] Badan Pusat Statistik. 2012. Statistik Indonesia 2012. Jakarta.

[BPS] Badan Pusat Statistik. 2012. Kabupaten Bangka Selatan Dalam Angka 2012. Toboali. 
[BPTP] Balai Pengkajian Teknologi Pertanian Provinsi Kepulauan Bangka Belitung. 2006. Penyusunan Peta Pewilayahan Komoditas Berdasarkan Zona Agro Ekologi (ZAE) Melalui Analisis Terrain Skala 1:50.000 di Kabupaten Bangka Selatan. Pangkalpinang.

Dinas Kehutanan. 2012. Statistik Kehutanan Provinsi Kepulauan Bangka Belitung tahun 2012. Pangkalpinang, Kepulauan Bangka Belitung.

Estes, J.E. and D.S. Simonett. 1975. Fundamental of image interpretation. Chapter 14. In R.G. Reeves (Ed.). Manual of Remote Sensing. American Society for Photogrammetry and Remote Sensing. p. $25-45$.

Ismet, M. 2007. Tantangan mewujudkan kebijakan pangan yang kuat [Ulasan]. Majalah Pangan XVI: 3-9. Jakarta: BULOG. http://www. majalahpangan.com/artikel. pHp?id=97 (diakses 20 September 2013).

Kementerian Pertanian. 2012. Perencanaan Tenaga Kerja Sektor Pertanian 2012-2014. Jakarta.

Lintz, Jr.J. and D.S. Simonett. 1976. Remote Sensing of Environment. Addison Wesley Pub. Co. Advanced Book Program. Reading, Massachusetts. 694 pp.

Pemerintah Provinsi Kepulauan Bangka Belitung. 2012. Situs Resmi Pemerintah Provinsi Kepulauan Bangka Belitung. 2013. http://www.babelprov.go.id /content/sektor-pertanian-kehutanan (diakses 26 Februari 2013).

Pemerintah Republik Indonesia. 2009. Undang-undang Nomor 41 Tahun 2009 tentang Perlindungan Lahan Pertanian Berkelanjutan. Sekretariat Negara, Jakarta.

Pemerintah Republik Indonesia. 2012. Peraturan Menteri Pertanian No. 50 Tahun 2012 tentang Pedoman Pengembangan Kawasan Pertanian. Sekretariat Negara, Jakarta.

Pemerintah Republik Indonesia. 2012. Peraturan Pemerintah Nomor 12 tahun 2012 tentang Insentif Perlindungan Lahan Pertanian Pangan Berkelanjutan. Sekretariat Negara, Jakarta.

Pemerintah Republik Indonesia. 2012. Peraturan Pemerintah Nomor 18 Tahun 2012 tentang Pangan. Sekretariat Negara, Jakarta.

Qiu, H.J., W.B. Zhu, H.B. Wang, and X. Cheng. 2007. Analysis and design of agricultural sustainability indicators system. Agric. Sci. in China., 6: 475-486.

Sugiyono. 2006. Statistika untuk Penelitian. Cetakan ke-7. CV Alfabeta. Bandung.

Zaki, A.R., A. Hakim, dan F. Nurani. 2012. Dampak sosial ekonomi pertambangan minyak dan gas Banyu Urip Kabupaten Bojonegoro. J Adm Publik., 2: 1-7. 